\title{
Evaluation of Solubility of Luting Cements in Different Solutions
}

\author{
Alma Gavranović-Glamočc ${ }^{*}$ Muhamed Ajanović ${ }^{1}$, Lejla Kazazić ${ }^{1}$, Sanela Strujić-Porović ${ }^{1}$, Selma Zukić ${ }^{2}$, Selma \\ Jakupović ${ }^{3}$, Alma Kamber-Ćesir ${ }^{1}$, Lejla Berhamović ${ }^{1}$ \\ ${ }^{1}$ Department of Prosthodontics, Faculty of Dentistry with Clinics, University of Sarajevo, Bosnia and Herzegovina, ${ }^{2}$ Department \\ of Dental Morphology, Anthropology and Forensics, Faculty of Dentistry with Clinics, University of Sarajevo, ${ }^{3}$ Department \\ of Restorative Dentistry with Endodontics, Faculty of Dentistry with Clinics, University of Sarajevo, Bosnia and Herzegovina
}

Correspondence: alma.glamoc@gmail.com; Tel.: + 38733214 249; Fax.: + 38733443395

Received: 16 April 2020; Accepted: 29 April 2020

\begin{abstract}
Objective. To evaluate and compare the solubility of three luting cements in three different solutions: distilled water and artificial saliva with different $\mathrm{pH}$ values (7.4 and 3.0). Materials and Methods. Resin-modified glass-ionomer cement (GC Fuji Plus) and two resin cements (Multilink Automix and Variolink II) were used. A total of 45 specimens, 15 specimens (15x1 mm) for each cement, were prepared according to ISO standard 4049:2009. The solubility of the cements was calculated by weighing the specimens before and after immersion and desiccation. Values of solubility in water (Wsl) in microgram $/ \mathrm{mm}^{3}$ for each of the five specimens were calculated using the following formula (ISO 4049:2009): Wsl=(m1-m3)W.

The Mann-Whitney U nonparametric statistical method and Post hoc sample comparisons were applied. Results. GC Fuji Plus showed statistically significant higher solubility in comparison with Variolink II and Multilink Automix in all three solutions. In acidic artificial saliva ( $\mathrm{pH}$ 3.0) Multilink Automix showed significantly higher values of solubility compared to Variolink II $(\mathrm{P}<0.016)$. By studying the effect of $\mathrm{pH}$ value on the solubility of GC Fuji Plus cement, significantly higher values of solubility in $\mathrm{pH} 3.0$ artificial saliva were confirmed $(\mathrm{P}<0.009)$. The influence of the surrounding $\mathrm{pH}$ value on the solubility of the resin cements Multilink Automix and Variolink II was researched. No statistically significant difference was found. Conclusion. Solubility values were mainly influenced by the proportion of hydrophilic matrix, the type and composition of filler, and the $\mathrm{pH}$ value of the solutions.
\end{abstract}

Key Words: Solubility - Resin Modified Cements - Resin Cements • Prosthodontics.

\section{Introduction}

Permanent cementing and the selection of cement are extremely important factors for the long-term success of fixed prosthodontics therapy. Success also depends on the type of restoration, the clinical circumstances and the characteristics of the cement material. Although achieving the optimal retentive and resistant form of the prepared tooth is of primary importance, the role of dental cement is not negligible $(1,2)$.

Cement fills the space between the teeth and the restoration, and protects them from the harmful effects of occlusal force, while at the same time

* ORCID ID: http://www.orcid.org/0000-0001-5232-868X representing a barrier against microbial leakage. At the margin of the preparation, dental cement is in constant contact with saliva, a fluid containing a spectrum of proteins with different antimicrobial characteristics dissolved in water $(3,4)$. Good dental cement must be resistant to disintegration and dissolution where a thin layer of cement may possibly be completely dissolved, creating a space susceptible to plaque accumulation and secondary caries, which, if not observed in time, leads to tooth decay, infraction of the margin of restoration, and debonding of the restoration (5-8).

Numerous authors have pointed out that water may contribute to the failure of adhesive to bond with dentin $(5,9-12)$. Solubility is therefore an im- 
portant feature in the assessment of the clinical durability of dental cements, and has been the subject of numerous experimental and clinical studies (6, 10-14). Tests which examine these changes in dental cements should be performed in saliva. There is a wide range of $\mathrm{pH}$ values in the oral cavity under different conditions, however, the $\mathrm{pH}$ value of the oral cavity is considered to be slightly alkaline. Short-term changes in its $\mathrm{pH}$ value occur, in terms of increased acidity due to the bacterial metabolism of dental plaque. However, the unstable nature of natural saliva makes it unsuitable for standardized in vitro studies. Artificial saliva that reacts with the test materials in a way similar to natural saliva, is a basic requirement for an artificial oral environment. In vitro tests require the chemical conditions that exist in the oral cavity. ISO 4049 is the standard and most commonly used method for testing the water sorption and solubility of resin-based cements (15). In this study, the method described by ISO 4049 was performed completely, except that the samples, besides storage in distilled water, were stored in artificial saliva with two different $\mathrm{pH}$ values. The choice of $\mathrm{pH}$ value of the artificial saliva followed the logic: a slightly alkaline buffered solution mimics normal natural saliva; the acid solution ( $\mathrm{pH} 3.0$ ) mimics the conditions in the oral cavity after the action of a bacterial biofilm; and the third solution (distilled water) has a neutral $\mathrm{pH}$. In this way, we tried to simulate the dynamics of change in the $\mathrm{pH}$ of saliva, whose $\mathrm{pH}$ is from 6.2 to 7.6 , and changes under the influence of a number of factors (4, 16-19).

The multiple purposes of dental cements have led to different types of cements with various properties coming onto the market, as no material has yet been developed that can meet all the necessary requirements. With the expansion of aesthetic dentistry, resin-based cements are becoming increasingly important and are unavoidable in the adhesive cementing of ceramic crowns and bridges, inlays, onlays, ceramic veneers, composite post and orthodontic braces (20-22).

Resin-modified glass-ionomer cements may be used for cementing restorations made of ceramics and, in addition to this, they are widely used for cementing metal-ceramic restorations and cast posts as well. They have good mechanical properties, limited solubility and radiocontrast similar to composite cements, and easy handling and fluoride release with a caries-protective effect, similar to conventional glass ionomer cements (21-24).

Knowing the characteristics of the cement material will aid the appropriate choice of luting cement and thus the durability of fixed prosthodontic restorations, and decrease the possibility of the occurrence of secondary caries, postoperative hypersensitivity, pulpal inflammation and periodontal diseases $(11,25-29)$. The solubility of dental cements has been the subject of numerous studies, but studies of solubility in artificial saliva of different $\mathrm{pH}$ values are rare. However, changes in the $\mathrm{pH}$ value of the environment might affect the solubility of different dental luting cements.

The objective of this research was to evaluate and compare the solubility of three luting cements for permanent cementation in three different solutions: distilled water and artificial saliva with different $\mathrm{pH}$ values (7.4 and 3.0), and to examine the influence of the $\mathrm{pH}$ value of the artificial saliva on solubility.

\section{Material and Methods}

The dental cements used in this study are shown in Table 1.

Fifteen specimens of each cement were made according to ISO specification 4049:2009 (15). Specimens were made in Teflon molds with an inner diameter of $15 \pm 0.1 \mathrm{~mm}$ and thickness of $1 \pm 0.1$ $\mathrm{mm}$. Preparation of specimens of GC Fuji Plus selfcuring cement (GC Corporation Tokyo, Japan), a resin modified cement, was carried out as follows: a $50 \mu \mathrm{m}$ thick polyester film was put on a metal plate and over it the mold in which the cement was slightly overfilled, to minimize air inclusion. Another polyester film was put on top of the material in the mold and covered with a second metal plate to remove the excess material. The metal plates were bound together by clamps, and the specimens were immediately stored in an incubator at $37 \pm 1^{\circ} \mathrm{C}$. After 60 minutes the specimens were re- 
Table 1. Name, Type and Main Component of Cement

\begin{tabular}{|c|c|c|}
\hline Name of cement and manufacturer & Type of cement & Main components \\
\hline $\begin{array}{l}\text { GC Fuji PLUS CAPSULE (reinforced glass- } \\
\text { ionomer cement) GC Corporation Tokyo, } \\
\text { Japan }\end{array}$ & $\begin{array}{l}\text { Resin-modified } \\
\text { glass-ionomer } \\
\text { cement. }\end{array}$ & $\begin{array}{l}\text { Powder: aluminofluorosilicate glass } \\
\text { Liquid: polyacrylic acid, HEMA, metadimethacrylate, water. }\end{array}$ \\
\hline $\begin{array}{l}\text { Multilink Automix IvoclarVivadent AG; } \\
\text { FL-9494 Schaan, Liechtenstein. }\end{array}$ & Resin cement. & $\begin{array}{l}\text { Monomer: dimethacrylate, HEMA; Inorganic filler ( } 40 \%) \text { : } \\
\text { barium glass, ytterbium trifluoride, spheroid mixed oxide; } \\
\text { Additional content: catalysts, stabilizer, pigments. The mean particle } \\
\text { size is } 0.9 \mu \mathrm{m} \text {. }\end{array}$ \\
\hline $\begin{array}{l}\text { Variolink II } \\
\text { IvoclarVivadent AG; FL-9494 Schaan, } \\
\text { Liechtenstein. }\end{array}$ & Resin cement. & $\begin{array}{l}\text { Monomer: Bis-GMA, urethane dimethacrylate, } \\
\text { triethylenglicoldimethacrylate; Inorganic filler ( } 40 \%) \text { : } \\
\text { barium glass, Ba-Al-fluorsilicate glass, ytterbium trifluoride, spheroid } \\
\text { mixed oxide; Additional content: catalysts, stabilizers, pigments. The } \\
\text { mean particle size is } 0.7 \mu \mathrm{m} \text {. }\end{array}$ \\
\hline
\end{tabular}

moved from the mold. Specimens were trimmed and polished with 1000 grit silicon carbide grinding paper until a final diameter of $14.9 \pm 0.1 \mathrm{~mm}$ was attained. The diameter was measured with a TESA 0-25 mm micrometer for external measurements, with measurement accuracy of $0.001 \mathrm{~mm}$ (TESA, Renens, Switzerland).

For preparation of the specimens of the dual cure cements (Mulitlink Automix and Variolink II), the metal plate was replaced by a glass plate, over which polymerization of specimens was performed. The light was tested for light output by means of a digital radiometer (Bluephase Meter, Ivoclar Vivadent, Schaan/Liechtenstein). The light tip of the polymerization lamp (Bluephase 20, Ivoclar Vivadent Ag, and FL-9494 Schaan/Liechtenstein) was directed over the center of the specimens for the correct time of exposure, and then eight peripheral overlapping sectors were irradiated for 20 seconds each, until the whole area had been irradiated. After that, the lower side of the specimens was polymerized in the same way as the upper one. The specimens were immediately stored in an incubator at $37 \pm 1^{\circ} \mathrm{C}$ for 60 minutes, and then finished as the previous one. After preparation was complete, all specimens were stored in desiccators with silicate gel, and the entire set was stored in an incubator maintained at $37 \pm 1^{\circ} \mathrm{C}$. After 22 hours, the specimens were moved into another desiccator maintained at $23 \pm 1^{\circ} \mathrm{C}$ for 2 hours, and, after that, weighed on an analytical balance, (Sartorius LE244S 0-240 g) with accuracy of measurement of $0.0001 \mathrm{~g}$ (Sartorius Göttingen, Germany) until a constant mass of $\mathrm{m} 1$ was obtained or until the mass loss of each specimen was not less than $0.01 \mathrm{mg}$ over $24 \mathrm{~h}$. The diameter$\mathrm{r}(\mathrm{mm})$ and thickness-h $(\mathrm{mm})$ of each specimen was measured by micrometer, with accuracy up to $0.001 \mathrm{~mm}$ according to the ISO specification, and the volume-V $\left(\mathrm{mm}^{3}\right)$ was calculated according to the formula: $V=\pi \times r^{2} x h$.

Five specimens of each cement were immersed in distilled water, five specimens in artificial saliva $\mathrm{pH}$ value 7.4, and five specimens were immersed in artificial saliva $\mathrm{pH}$ value 3.0. All specimens were stored in a Culture Incubator (Ivoclar Vivadent, Schaan / Liechtenstein) at $37 \pm 1^{\circ} \mathrm{C}$ for 7 days. Tomasi's solution of artificial saliva $\mathrm{pH}$ value 7.4 was prepared for this research at the Department of Chemistry, Faculty of Natural Science and Mathematics of Sarajevo University. (3) In order to obtain a pH-value of 3.0, Tomasi's solution was modified by the intentional acidification of the solution.

After the first day of storage, the specimens were taken out of the liquid, washed entirely with water, air dried for 15 seconds, and weighed one minute after they were taken out of the water to record their mass. The same procedures were repeated at $48 \mathrm{~h}, 72 \mathrm{~h}, 96 \mathrm{~h}$ and 168 hours, when the final mass-m2 from the second cycle was recorded. This second cycle showed the combination of water sorption and dissolution of the soluble components from the specimens.

After weighing in the second cycle the specimens were stored in the desiccator and incubator again in the same way as in the initial cycle, and afterwards the $\mathrm{m} 3$ mass was recorded. This third 
cycle allowed measurement of the mass loss. The values of solubility in water (Wsl) in microgram/ $\mathrm{mm}^{3}$ for each of the five specimens were calculated using the following formula (ISO 4049:2009): $\mathrm{Wsl}=(\mathrm{m} 1-\mathrm{m} 3) / \mathrm{V}$, where $\mathrm{m} 1=$ mass of specimens $(\mu \mathrm{g})$ before immersion, $\mathrm{m} 3$ = mass of refined specimens $(\mu \mathrm{g})$ and $\mathrm{V}$-volume of specimens $\left(\mathrm{mm}^{3}\right)$.

\section{Statistical Analysis}

All data were analyzed using the IBM SPSS v.17 statistical software. Preliminary statistical analyses were carried out to determine the distribution of the dependent variables, and to decide on the application of parametric or nonparametric statistical methods. Since the dependent variables were asymmetric, the Mann-Whitney U nonparametric statistical method was applied. As the required alpha level of significance for rejection of the null hypothesis, the level 0.05 (5\%) was taken. To avoid first category statistical error, in subsequent (Post hoc) sample comparisons, matching with Bonferroni was used, where the required alpha level of significance of $5 \%$ was corrected, i.e. divided by the comparison number $(\mathrm{P}<0.05 / 3=\mathrm{P}<0.017)$.

\section{Results}

The arithmetical means and standard deviations of solubility for each dental cement in three different solutions are shown in Table 2. GC Fuji Plus showed statistically significantly higher solubility in comparison with Variolink II $(\mathrm{P}<0.009)$ in all three solutions (distilled water, artificial saliva of $\mathrm{pH}$ values 7.4 and 3.0). Post hoc comparisons are shown in Table 3.

Table 2. Mean and Standard Deviation of Solubility between Groups

\begin{tabular}{lllll}
\hline Solubility in different solutions cement & Type of cement & N & Mean & SD \\
\hline \multirow{3}{*}{ Solubility-distilled water } & GC Fuji Plus & 5 & 7.12 & 2.67 \\
\cline { 2 - 5 } & Multilink Automix & 5 & -3.06 & 2.80 \\
\cline { 2 - 5 } & Variolink II & 5 & -5.25 & 0.28 \\
\hline \multirow{3}{*}{ Solubility-artificial saliva pH 7.4 } & GC Fuji Plus & 5 & 3.46 & 3.16 \\
\cline { 2 - 5 } & Multilink Automix & 5 & -3.20 & 2,92 \\
\cline { 2 - 5 } & Variolink II & 5 & -5.29 & 0.07 \\
\hline \multirow{3}{*}{ Solubility-artificial saliva pH 3.0 } & GC Fuji Plus & 5 & 13.22 & 2.90 \\
\cline { 2 - 5 } & Multilink Automix & 5 & -4.10 & 2.29 \\
\cline { 2 - 5 } & Variolink II & 5 & -5.41 & 0.13 \\
\hline
\end{tabular}

Table 3. Post Hoc Comparison between Groups

\begin{tabular}{llll}
\hline \multirow{2}{*}{ Type of cement } & GC Fuji Plus & Multilink Automix & Variolink II \\
\cline { 2 - 4 } & Solubility - distilled water & & \\
\hline GC Fuji Plus & - & $\mathrm{P}=0.009(0.828)$ & $\mathrm{P}=0.009(0.826)$ \\
\hline Multilink Automix & $\mathrm{P}=0.009(0.828)$ & $\mathrm{N}$ & $\mathrm{NS}$ \\
\hline Variolink II & $\mathrm{P}=0.009(0.826)$ & $\mathrm{NS}$ & \\
\cline { 2 - 4 } & $\mathrm{S}$ Solubility-artificial saliva $\mathrm{pH} 7.4$ & & $\mathrm{P}=0.009(0.828)$ \\
\hline GC Fuji Plus & - & $\mathrm{NS}$ & $\mathrm{NS}$ \\
\hline Multilink Automix & $\mathrm{NS}$ & - & - \\
\hline Variolink II & $\mathrm{P}=0.009(0.828)$ & $\mathrm{NS}$ & \\
\hline & $\mathrm{S}$ Solubility-artificial saliva $\mathrm{pH} 3.0$ & & $\mathrm{P}=0.009(0.828)$ \\
\hline GC Fuji Plus & - & $\mathrm{P}=0.009(0.826)$ & $\mathrm{NS}$ \\
\hline Multilink Automix & $\mathrm{P}=0.009(0.826)$ & - & - \\
\hline Variolink II & $\mathrm{P}=0.009(0.828)$ & $\mathrm{NS}$ & \\
\hline
\end{tabular}

Mann Whitney U test; $\mathrm{P}$ (effect size $=\mathrm{Z} / \sqrt{ } \mathrm{n}$ ); NS=Not statistically significant. 
A statistically significant difference was found between the solubility in the distilled water solution and the artificial saliva with $\mathrm{pH}$ value 3.0 between Multilink Automix and GC Fuji Plus $(\mathrm{P}<0.009)$. The samples of GC Fuji Plus cement showed a higher degree of solubility. In the solution of artificial saliva with $\mathrm{pH}$ value $7.4(\mathrm{P}<0.05 / 3=0.017)$, no statistically significant difference $(\mathrm{P}=0,024)$ in solubility between Multilink Automix and GC Fuji Plus was confirmed. However, at a level of significance of $\mathrm{P}<0.05$, it would show statistical significance. Post hoc comparisons are shown in Table 3.

No statistically significant difference was found in solubility levels between the cements Multilink Automix and Variolink II in distilled water $(\mathrm{P}=0.173)$, or in the artificial saliva solution with $\mathrm{pH}$ of value $7.4(\mathrm{P}=0.600)$. In artificial saliva with a $\mathrm{pH}$ of 3.0, a statistically significant difference was detected in the solubility of cements Multilink Automix and Variolink II, with a probability of $\mathrm{P}<0.016$. Multilink cement showed a higher degree of solubility. Post hoc comparisons are shown in Table 3.

Analysis of the effect of $\mathrm{pH}$ value on the solubility of dental cements confirmed a statistically significant difference $(\mathrm{P}<0.009)$ of solubility level in GC Fuji Plus cement between the solutions of artificial saliva with $\mathrm{pH} 7.4$ and artificial saliva with pH 3.0. GC Fuji Plus cement showed a higher degree of solubility in artificial saliva with $\mathrm{pH}$ 3.0. Post hoc comparisons are shown in Table 4.

Table 4. Post hoc Comparison between Groups of Solubility (GC Fuji Plus)

\begin{tabular}{llll}
\hline Solubility & $\begin{array}{l}\text { Distilled } \\
\text { water }\end{array}$ & $\begin{array}{l}\text { Artificial saliva } \\
\mathrm{pH} 7.4\end{array}$ & $\begin{array}{l}\text { Artificial saliva } \\
\mathrm{pH} \mathrm{3.0}\end{array}$ \\
\hline Distilled water & - & $\mathrm{NS}$ & $\mathrm{NS}$ \\
\hline $\begin{array}{l}\text { Artificial saliva } \\
\text { pH 7.4 }\end{array}$ & $\mathrm{NS}$ & - & $\mathrm{P}=0.009(0.828)$ \\
\hline $\begin{array}{l}\text { Artificial saliva } \\
\text { pH 3.0 }\end{array}$ & $\mathrm{NS}$ & $\mathrm{P}=0.009(0.828)$ & - \\
\hline
\end{tabular}

Mann Whitney $\mathrm{U}$ test; $\mathrm{P}$ (effect size $=\mathrm{Z} / \sqrt{ } \mathrm{n}$ ); NS=Not statistically significant.

The influence of the environmental $\mathrm{pH}$ value on the solubility of Multilink Automix cement was researched. No statistically significant influence of the saliva's $\mathrm{pH}$ value on Multilink Automix cement was confirmed, with a probability of $\mathrm{P}=0.583$. Studying the effect of $\mathrm{pH}$ values on the solubility of Variolink II dental cement no statistically significant difference was found in levels of solubility of Variolink II cement in the different solutions, with a probability of $\mathrm{P}=0.248$.

\section{Discussion}

The resin-modified glass ionomer cement Fuji Plus exhibited significantly higher solubility when compared with the resin cements (Variolink II and Multilink) in all solutions, expect in the solution of artificial saliva with a $\mathrm{pH}$ value of 7.4 , where no statistically significant difference in solubility was confirmed between Multilink Automix and GC Fuji Plus at the level of significance of $\mathrm{P}=0.024$. However, at the level of significance of $\mathrm{P}<0.05$ it would show statistical significance. The hydrophilic nature of resin-modified glass-ionomer cements (that include HEMA in their composition) most probably contributed to the significantly higher solubility compared to the resin cements in our study (30-32). The values which Mortier obtained for Fuji II resin modified cement completely correspond to our results, as well as the fact that in their study resin modified glass ionomers showed significantly higher solubility values than composite cements (12).

The mean solubility values in our study for Fuji Plus are somewhat lower than the values obtained by Mese and Gerdole in their research $(11,33)$, which may be explained by our use of encapsulated cement and mechanical mixing, in comparison to the manually mixed cements used by these authors. The mixing process can lead to the formation of air bubbles, which may increase the surface exposed to water, which leads to the formation of inhibitory zones of unpolymerized material, and accelerates the water sorption and solubility of cement $(10,34,35)$.

Knobloch, Al-Shekhli obtained similar results to ours with respect to the solubility of resin modified glass ionomer cements, which showed significantly higher solubility compared to composite ce- 
ments $(21,36)$. Yohsida et al. also concluded that composite cements were significantly less soluble than conventional cements, but the results cannot be compared directly with our results because the authors expressed the solubility results in percentages (28). Although resin modified glass ionomer cement showed higher solubility values than composite cements, the presence of the resin matrix in resin-modified cements reduces the diffusion of solvent into the cement, and there is consequently less solubility compared to conventional glass ionomers (37). For significantly lower solubility values than conventional cements (zinc phosphate, polycarboxylate and ionomer cement), the choice of luting cement for metal-ceramic restorations, while ensuring adequate retentive and resistant tooth form and good marginal adaptation, would be resin-modified glass ionomer cement.

When composite cements, unlike resin modified glass ionomers, must be used for the bond, the locus minoris in the bonding chain must be kept in mind. When predicting prosthetic durability, the contact surface of the tooth and cement must be taken into account as well. Numerous studies have shown that adhesive systems have water sorption and solubility values 30 to 150 times greater than the corresponding resin based materials. The adhesive is exposed to oral fluids on a small surface, but has significant contact with dentin. Dentin tubules occupy about $20-40 \%$ of the median coronary dentin surface, and water accounts for about $22 \%$ of the volume of dentin (33). As for the water, $75 \%$ of its entire quantity is in the tubules, and $25 \%$ is bound in a mineralized matrix around the mineral crystals or collagen (33).

Over time, tubular fluids may damage the adhesive that connects the dentin to the restoration. This should be borne in mind when applying dental cements clinically and making a decision when selecting the appropriate cement. If this fact is taken into account, the importance of resin-modified cements in daily clinical practice is not diminished. With respect to the solubility in different $\mathrm{pH}$ values of saliva, with a demanding alpha level of Bonferroni adaptation $(\mathrm{P}<0.05 / 3=0.017)$, a statistically significant $(\mathrm{P}<0.009)$ difference in the solu- bility level of GC Fuji Plus cement was confirmed between artificial saliva with $\mathrm{pH} 7.4$ and artificial saliva with $\mathrm{pH}$ 3.0.

These results correspond with the results of Hajmiragh and Bharali, which confirmed the higher solubility of conventional cements, but also the resin modified glass ionomer and composite cements in saliva with a lower $\mathrm{pH}(38,39)$. These authors report that, in addition to $\mathrm{pH}$, the solubility of the cement is influenced by the storage time, the concentration of solvent in the solution, the shape and thickness of the sample, as well as the ratio of powder to liquid in the cement (39).

Yanikoglu et al. found significantly higher solubility of cements stored in an acidic solution in their study. They tested the solubility of zinc phosphate, polycarboxylate and conventional glass ionomer cement, whereby the glass ionomer cements showing the lowest solubility (40). The positive effect of an acidic over a neutral solution is the greater ability to release fluoride in resin modified glass ionomer cements (41).

As we have already pointed out, composite cements are less soluble than glass ionomer cements. Our solubility results are consistent with the data found in the literature; composite cements dissolve less than resin modified glass-ionomer cements $(11,21,28,34,37)$. However, all the materials in the study showed some degree of solubility, i.e. they all interacted with water. The interaction between resin-based cements and water involves two opposing phenomena: the first is water sorption, which leads to the swelling of the material and an increase in weight, and the second is dissolution of materials (fillers or monomers) in the water. Release of unreacted monomers or fillers that will dissolve in water will result in weight loss, which we define as solubility $(11,42)$. It has also been shown that a portion of the absorbed water tightly bound to the resin matrix cannot be removed (31). The part of the water that is loosely bound to the resinous matrix after the drying period will disappear, but a certain amount of water remains inside the material. Therefore, when the amount of water which remains bonded to the resin matrix is greater than the amount of components lost 
during the desiccation process, this will result in negative solubility values, suggesting an obvious gain in mass $(11,31,32)$. Ortengren explains this by the possibility of the precipitation of particles within the solute material in which the samples were stored, or by the formation of metal hydroxide on the surface of the particles as a product of the hydrolysis reaction, which will also result in an increase in mass (32). In our study, negative solubility values were obtained for both composite cements. It should be noted that these values are in accordance with the values for solubility prescribed by the ISO standard. On the other hand, the weld volume of the polymer is subjected to a certain degree of dissolution, which is highly correlated with the degree of conversion of the material, i.e. the conversion of the monomer to a polymer. The conversion of monomers to a polymer network is never complete. It is also influenced by the type of filler and its treatment, as well as by the presence of air bubbles in the material (31). The Mann Whitney test found no statistically significant difference in solubility levels between Multilink Automix and Variolink II cements $(\mathrm{P}=0.173)$ in distilled water and saliva $\mathrm{pH} 7.4(\mathrm{P}=0.600)$. A statistically significant difference was detected in Multilink Automix cements (Mean rank $=7.80$ ) and Variolink II (Mean rank $=3.2$ ) in the solution of artificial saliva with a $\mathrm{pH}$ value of 3.0 , with a probability of $\mathrm{P}<0.016$, which can be explained by the chemical composition of these cements, different compositions and ratio matrix and fillers. Multilink Automix contains HEMA, which flows more readily in water than Bis-GMA because of its lower molecular weight and hydrophilic chemical structure (43). The data from our study correlate with the data of Vrochari, who obtained negative solubility values for Multilink Automix (31). The solubility results obtained by Mese et al. for Variolink II completely correspond with ours (11).

Our results are also in agreement with those of Berger et al., who examined the sorption and solubility of three restorative composites with different filler contents. These authors obtained a value of -4.0 (2.9) for the Filtek composite tested (44). These authors state that it is possible that not all the water was drained during the desiccation process and that negative values were obtained as a result. Some authors recommend a longer sample desiccation period (45). Swizero et al. tested the solubility of the Z 250 micro hybrid composite, and their results were consistent with ours (46). When studying the effect of $\mathrm{pH}$ on the solubility of Variolink II dental cements $(\mathrm{P}=0.248)$ and Multilink Automix ( $\mathrm{P}=0.583)$, no statistically significant difference in levels of solubility between different solutions was confirmed. Our results correlate with those of Toledano et al., who found that $\mathrm{pH}$ values had no effect on the solubility of composite cements (47).

Knobloch examined the solubility of cements in lactic acid, and found no significant differences in solubility between resin-based materials (21). Contrary to these studies, the study of Ortengren et al. concluded that solubility depends on the $\mathrm{pH}$ value of the solution, where solubility was reduced to $\mathrm{pH} 4$ and $\mathrm{pH} 6$, and increased to $\mathrm{pH} 8$ (32). The influence of low $\mathrm{pH}$ on the wear of composite cements was also investigated by Buchalla, who concluded that an acidic environment had little effect on the resistance and wear of the composite cements (48).

Considering the above, higher solubility rates of composite cements are expected in the oral cavity. Tomas' solution of artificial saliva used in our study had no enzymes in its composition, and higher values for the tested parameters may be expected in the oral cavity. The presence of the enzyme may degrade the polymer through side-chain attacks, thereby producing potentially harmful by-products, as well as deteriorating the properties of the composite mesh (48) and reducing the material's wear resistance $(49,50)$.

The quality of the network formed during the polymerization process will also dictate how much molecular uptake and swelling occurs when the polymer is submerged in the solvent. It is important to ensure the optimum conversion of the monomer to a polymer, to ensure optimal mechanical properties, and to resist mechanical and chemical deterioration $(46,51)$. In complex oral conditions, we cannot expect maximum polym- 
erization. Different clinical situations present a challenge for the use of the recommended polymerization technique, meaning the availability of the light source, its direction, and the preparation of the surrounding tissues $(46,52)$. Due to the low solubility of both composite cements used in our research, they are good choices in clinical practice. Both cements have a very wide spectrum of indication, where Multilink Automix is a self-cure, with optional light cure, and contains amines that may discolor the restoration and should be avoided when cementing ceramic veneers. Although the resin modified glass ionomer cement showed higher solubility values, this does not minimize the importance of its application in clinical practice in conventional cementation, since it has superior properties to conventional glass-ionomer, and a simpler use procedure than composite cement.

\section{Conclusion}

The resin modified glass-ionomer cement Fuji Plus showed the significantly highest solubility values of all three examined solutions. Multilink Automix and Variolink II were found to comply with ISO requirements regarding solubility. The values of solubility were found to depend on the matrix hydrophilicity, the type and composition of the filler, and degree of polymerization. The $\mathrm{pH}$ value of the artificial saliva affected the solubility of the resin modified glass-ionomer cement.

\section{What Is Already Known on this Topic:}

There are numerous studies of the solubility of dental cements. Solubility of dental cements is an important factor in evaluation of their clinical durability and hence the durability of fixed prosthetic restoration. Knowing the properties of cement material enables the appropriate choice of cement for permanent cementation of dental restoration.

\section{What this Study Adds:}

Studies of the solubility of dental cements in artificial saliva are rare. This research contributes to the knowledge about the solubility of dental cements in artificial saliva of various $\mathrm{pH}$ values, mimicking conditions in the oral cavity.

Acknowledgments: We thank GC EEO (Bosnia \& Herzegovina) and Ivoclar Vivadent AG (Schaan Liechtenstein) for material support. Special thanks to the Institute of Metrology of Bosnia and Herzegovina, Laboratory for Mass, as well as the Department of Chemistry, Faculty of Natural Sciences and Mathematics, University of Sarajevo, for help in measuring and preparing the solutions.

Authors' Contributions: Conception and design: AGG and SZ; Acquisition, analysis and interpretation of data: SZ, SSP, AKĆ and MA; Drafting the article: SJ and AGG; Revising it critically for important intellectual content: SSP, SZ and AKĆ; Approved final version of the manuscript: AGG and MA.

Conflict of Interest: The authors declare that they have no conflict of interest. We had material support from GC EEO (Bosnia \& Herzegovina) and Ivoclar Vivadent AG (Schaan Liechtenstein). We had support in measuring and solution preparation from the Institute of Metrology of Bosnia and Herzegovina, Laboratory for Mass, and the Department of Chemistry, Faculty of Natural Sciences and Mathematics, University of Sarajevo.

\section{References}

1. Edelhoff D, Ozcan M. To what extent does the longevity of fixed dental prostheses depend on the function of the cement? Working Group 4 materials: cementation. Clin Oral Implants Res. 2007;18 Suppl 3:193-204. Erratum in: Clin Oral Implants Res. 2008;19(3):326-8.

2. Rosenstiel SF, Land MF, Crispin BJ. Dental luting agents: A review of the current literature. J Prosthet Dent. 1998;80(3):280-301.

3. Preetha A, Banerjee R. Comparison of artificial saliva substitutes. Trends Biomater Artif Organs. 2005;18(2):178-86.

4. Inui T, Palmer RJ Jr, Shah N, Li W, Cisar JO, Wu CD. Effect of mechanically stimulated saliva on initial human dental biofilm formation. Sci Rep. 2019;9(1):11805.

5. Wingo K. Review of Dental Cements. J Vet Dent. 2018;35(1):18-27.

6. Giti R, Vojdani M, Abduo J, Bagheri R. The Comparison of Sorption and Solubility Behavior of Four Different Resin Luting Cements in Different Storage Media. J Dent (Shiraz). 2016;17(2):91-7.

7. Anusavice KJ. Phillips Science of Dental Materials. 11th ed. Philadelphia: Saunders; 2003.

8. Cattani-Lorente MA, Dupuis V, Payan J, Moya F, Meyer JM. Effect of water on the physical properties of resin-modified glass-ionomer cements. Dent Mater. 1999;15(1):71-8.

9. Chaves CA, de Melo RM, Passos SP, Camargo FP, Bottino MA, Balducci I. Bond strength durabilityof self-etching adhesives and resin cements to dentin. J Appl Oral Sci. 2009;17(3):155-60.

10. Dhanpal P, Yiu CK, King NM, Tay FR, Hiraishi N. Effect of temperature on water sorption and solubility of dental adhesive resins. J Dent. 2009;37(2):122-32. 
11. Mese A, Burow MF, Tyas MJ. Sorption and solubility of luting cements in different solutions. Dent Mater J. 2008;27(5):702-9.

12. Mortier E, Gerdolle DA, Jacquot B, Panighi MM. Importance of water sorption and solubility studies for couple bonding agent-resin-based filling material. Oper Dent. 2004;29(6):669-76.

13. Kim HJ, Bagheri R, Kim JK, Son JS, Kwon TJ. Influence of Curing Mode on the Surface Energy and Sorption/Solubility of Dental Self-Adhesive Resin Cements. Materials (Basel). 2017;10(2):129.

14. Tavangar MS, Jafarpur D, Bagheri R. Evaluation of Compressive Strength and Sorption/Solubility of Four Luting Cements. J Dent Biomater. 2017;4(2): 387-93.

15. International organization for standardization. Technical Committee: ISO/TC 106/SC 1. Dentistry-Polymer-Based Restorative Materials (ISO 4049). 4th ed. Geneva: International organization for standardization; 2009.

16. Hans R, Thomas S, Garla B, Dagli RJ, Hans MK. Effect of Various Sugary Beverages on Salivary pH, Flow Rate, and Oral Clearance Rate amongst Adults. Scientifica (Cairo). 2016;2016:5027283.

17. Ballal RK, Bhat SS, Ramdas SS, Ballal S. Effect of Chewing Bicarbonate-containing Sugar-free Gum on the Salivary pH: An in vivo Study. Int J Clin Pediatr Dent. 2016;9(1):35-8.

18. Duffo GS, Castillo Q. Development of an Artificial Saliva solution for Studying the Corrosion Behavior of Dental Alloys. Corrosion. 2004;60(6):594-602.

19. Borjian A, Ferrari CF, Anouf A, Touyz ZG. Pop-cola acids and tooth erosion: an in vitro, in vivo, electron-microscopic, and clinical report. In J Dent. 2010;2010:957842.

20. Scaminaci Russo D, Cinelli F, Sarti C, Giachetti L. Adhesion to Zirconia: A Systematic Review of Current Conditioning Methods and Bonding Materials. Dent J (Basel). 2019;7(3):74.

21. Knobloch LA, Kerby RE, McMillen K, Clelland N. Solubility and sorption of resin-based luting cements. Oper Dent. 2000;25(5):434-40.

22. Ganapathy D, Sathyamoorthy A, Ranganathan H, Murthykumar K. Effect of Resin Bonded Luting Agents Influencing Marginal Discrepancy in All Ceramic Complete Veneer Crowns. J Clin Diagn Res. 2016;10(12):ZC67-70.

23. Khoroushi M, Keshani F. A review of glass-ionomers: From conventional glass-ionomer to bioactive glass-ionomer. Dent Res J (Isfahan). 2013;10(4):411-20.

24. Yüksel E, Zaimoğlu A. Influence of marginal fit and cement types on microleakage of all-ceramic crown systems. Braz Oral Res. 2011;25(3):261-6.

25. Diaz-Arnold AM, Vargas MA, Haselton DR. Current status of luting agents for fixed prosthodontics. J Prosthet Dent. 1999;81(2):135-41.

26. Burke FJ. Trends in indirect dentistry: 3. Luting materials. Dent Update. 2005;32(5):251-4, 257-8, 260.
27. Piwowarczyk A, Lauer HC, Sorensen JA. Microleakage of various cementing agents for full cast crowns. Dent Mater. 2005;21(5):445-53.

28. Yoshida K, Tanagawa M, Atsuta M. In-vitro solubility of three types of resin and conventional luting cements. J Oral Rehabil. 1998;25(4):285-91.

29. Malacarne J, Carvalho RM, de Goes MF, Svizero N, Pashley DH, Tay FR, et al. Water sorption/solubility of dental adhesive resins. Dent Mater. 2006;22(10):973-80.

30. Selimović-Dragaš $M$, Huseinbegović A, Kobašlija S, Hatibović-Kofman Š. A comparison of the in vitro cytotoxicity of conventional and resin modified glass ionomer cements. Bosn J Basic Med Sci. 2012;12(4):274-8.

31. Vrochari AD, Eliades G, Hellwig E, Wrbas KT. Water sorption and solubility of four self-etching, self-adhesive resin luting agents. J Adhes Dent. 2010;1(1):39-43.

32. Ortengren U, Wellendorf H, Karlsson S, Ruyter IE. Water sorption and solubility of dental composites and identification of monomers released in an aqueous environment. J Oral Rehabil. 2001;28(12):1106-15.

33. Gerdolle DA, Mortier E, Jacquot B, Panighi MM. Water sorption and water solubility of current luting cements: an in vitro study. Quintessence Int. 2008;39(3):107-14.

34. Toledano M, Osorio R, Osorio E, Fuentes V, Prati C, Garcia-Godoy F. Sorption and solubility of resin based restorative dental materials. J Dent. 2003;31(1):43-50.

35. Asmussen E, Peutzfeldt A. Long-term fluoride release from a glass ionomer cement, a compomer, and from experimental resin composites. Acta Odontol Scand. 2002;60(2):93-7.

36. Al-Shekhli AWR. Solubility of four dental luting cements. J Int Dent Med Res. 2010;3(3):104-7.

37. Attar HE, Elhiny O, Salem G, Abdelrahman A, Attia M. A Twofold Comparison between Dual Cure Resin Modified Cement and Glass Ionomer Cement for Orthodontic Band Cementation. Open Access Maced J Med Sci. 2016;4(4):695-9.

38. Hajmiragha S, Nokar M, Alikhasi S, Nikzad H. Solubility of Three Luting Cements in Dynamic Artificial Saliva. J Dent (Tehran). 2008;5(3):95-8.

39. Bharali K, Das M, Jalan S, Paul R, Deka A. To Compare and Evaluate the Sorption and Solubility of Four Luting Cements after Immersion in Artificial Saliva of Different pH Values J Pharm Bioallied Sci. 2017;9(1):103-6.

40. Yanikoğlu N, Yeşil Duymuş Z. Evaluation of the Solubility of Dental Cements in Artificial Saliva of Different $\mathrm{pH}$ Values. Dent Mater J. 2007;26(1):62-7.

41. Czarnecka B, Nicholson JW. Ion release by resin-modified glass-ionomer cements into water and lactic acid solutions. J Dent. 2006;34(8):539-43.

42. Gavranović-Glamoč A, Ajanović M, Korać S, Zukić S, Strujić-Porović S, Alma Kamber-Ćesir A, et al. Evaluation of the water sorption of luting cements in different solu- 
tions. Evaluation of the water sorption of luting cements in different solutions. Acta Med Acad. 2017;46(2):124-32.

43. Moreira FC, Antoniosi Filho NR, Souza JB, Lopes LG. Sorption, solubility and residual monomers of a dental adhesive cured by different light-curing units. Braz Dent J. 2010;21(5):432-8.

44. Berger BS, Palialol ARM, Cavalli V, Giannini M. Characterization of water sorption, solubility and filler particles of light-cured composite resins. Braz Dent J. 2009;20(4):314-8.

45. Archegas LR, Caldas D, Rached RN, Vieira S, Souza E. Sorption and solubility of composites cured with quartztungsten halogen and light emitting diode light-curing units. J Contemp Dent Pract. 2008;9(2):73-80.

46. da Rocha Svizero N, Bruschi Alonso RC, Wang L, PalmaDibb RG, Atta MT, Perlatti D’Alpino PH. Kinetic of water diffusion and color stability of a resin composite as a function of the curing tip distance. Mat Res. 2012;15(4):60310.
47. Toledano M, Osorio R, Osorio E, Aguilera FS, Romeo A, de la Higuera B, et al. Sorption and solubility testing of orthodontic bonding cements in different solutions. J Biomed Mater Res B Appl Biomater. 2006;76(2):251-6.

48. Buchalla W, Attin T, Hellwig E. Brushing abrasion of luting cements under neutral and acidic conditions. Oper Dent. 2000;25(6):482-7.

49. Ferracane J. Hygroscopic and hydrolytic effects in dental polymer networks. Dent Mater. 2006;22(8):211-22.

50. Finer Y, Santerre JP. The influence of resin chemistry on a dental composite's biodegradation. J Biomed Mater Res A. 2004;69(2):233-46.

51. Goncalves F, Kawano Y, Pfeifer C, Stansbury JW, Braga RR. Influence of Bis-GMA, TEGDMA, and BisEMA contents on viscosity, conversion, and flexural strength of experimental resins and composites. Eur J Oral Sci. 2009;117(4):442-6.

52. Emami N, Soderholm KJ, Berglund LA. Effect of light power density variations on bulk curing properties of dental composites. J Dent. 2003;31(3):189-96. 